\title{
Separating Developmental and Environmental Effects on Fluctuating Asymmetry in Lythrum salicaria and Penthorum sedoides
}

\author{
Jennifer R. Milligan \\ Cleveland State University, jr_milligan@hotmail.com \\ Robert A. Krebs \\ Cleveland State University, r.krebs@csuohio.edu \\ Tarun K. Mal \\ Cleveland State University
}

Follow this and additional works at: https://engagedscholarship.csuohio.edu/scibges_facpub

Part of the Biology Commons

How does access to this work benefit you? Let us know!

\section{Recommended Citation}

Milligan, J. R., Krebs, R. A., \& Ma, T. K. (2008). SEPARATING DEVELOPMENTAL AND ENVIRONMENTAL EFFECTS ON FLUCTUATING ASYMMETRY IN LYTHRUM SALICARIA AND PENTHORUM SEDOIDES. International Journal Of Plant Sciences, 169(5), 625-630. doi:10.1086/533600

This Article is brought to you for free and open access by the Biological, Geological, and Environmental Sciences Department at EngagedScholarship@CSU. It has been accepted for inclusion in Biological, Geological, and Environmental Faculty Publications by an authorized administrator of EngagedScholarship@CSU. For more information, please contact library.es@csuohio.edu. 


\title{
SEPARATING DEVELOPMENTAL AND ENVIRONMENTAL EFFECTS ON FLUCTUATING ASYMMETRY IN LYTHRUM SALICARIA AND PENTHORUM SEDOIDES
}

\author{
Jennifer R. Milligan, ${ }^{1 * *}$ Robert A. Krebs, ${ }^{*}$ and Tarun K. Mal2,* \\ *Department of Biological, Geological, and Environmental Sciences, Cleveland State University, Cleveland, Ohio 44115, U.S.A.
}

\begin{abstract}
Environmental stress can disrupt developmental processes on biological, physiological, and chemical levels and thereby affect the symmetry of a trait. For this reason, fluctuating asymmetry is often proposed as a measure of stress encountered by an individual. One problem is that asymmetry may have multiple causes, including developmental noise and genetic background, and genetic differences may interact with any physiological stress imposed by the environment. The main objective of this research was to determine whether developmental noise and genetic stress can be separated from environmental effects on leaf asymmetry. The experiments were conducted on two wetland plants, Lythrum salicaria (purple loosestrife) and Penthorum sedoides (ditch stonecrop). Replicates of different genotypes were measured when young and after they matured, with the latter group grown under two nutrient treatments. The largest and healthiest leaf of each plant was measured for length, width, and differences in width between the left and right sides (measuring from the central vein at the widest point). Nutrient enrichment increased leaf asymmetry, while age reduced asymmetry in L. salicaria. However, leaf asymmetry changed only as a consequence of development in $P$. sedoides and decreased. Genotype did not affect asymmetry in either species.
\end{abstract}

Keywords: genetic variation, leaf asymmetry, nutrient stress, ontogeny, size, wetland plants.

\section{Introduction}

Developmental stability is the ability of an organism under varying environmental conditions and genetic backgrounds to develop an "ideal" form (Schmalhauzen 1949; Zakharov 1992). Developmental stability involves a collection of processes that buffer disruptions that would affect symmetry (Palmer 1994). These disruptions can take place on a cellular, physiological, or biochemical level (Palmer 1996; Polak 2003). Both genetic and environmental perturbations cause variation in symmetry. Different genotypes within a species or identical genotypes that face differing environmental conditions may vary in developmental stability (Møller and Swaddle 1997). The most commonly used index of developmental stability is fluctuating asymmetry (FA; Møller and Swaddle 1997). This asymmetry in bilaterally symmetrical organisms is usually described as distributions in measurements of right side minus left $(R-L)$.

An important assumption in studies involving FA as a measure of developmental stability is that the subtle asymmetries should not have a heritable basis (Leamy 2003). If variation in FA among individuals possesses a genetic and an environmental component, then FA might not be a predictable measure of developmental stability and therefore of environmental stress (Palmer 1994). There has been considerable debate on the significance of a genetic contribution to the asymmetry of a phenotype, which ranges between two extremes. Møller and Thornhill (1997) found significant heritability estimates that favor the idea of a substantial genetic contribution, while Leamy (1997) regards the genetic component as negligible. Woods

${ }^{1}$ Author for correspondence; e-mail: jr_milligan@hotmail.com.

${ }^{2}$ In memoriam.

Manuscript received July 2007; revised manuscript received October 2007. et al. (1999) have shown that heritability may be trait specific. Most often, the assumption that FA does not have a genetic component has been made (Leamy 2003), but few studies have actually tested whether this assumption holds before analyzing environmental causes of FA. For this reason, an ideal study for testing the sensitivity of FA as an indicator of environmental stress should distinguish between genetic and environmental effects (Sinclair and Hoffmann 2003).

In addition to the unknown genetic contribution to FA, the process of development alone can be taxing on an organism. Rapid growth results in high energy expenditure; however, energy may be limited in early life stages of an organism. In young fish, growth consumes a large portion of the available energy (Pederson 1997), and little information is known as to the degree to which asymmetry changes because of age. Swaddle and Witter (1997) suggest six hypotheses to explain how ontogeny can affect FA: (1) directional external cues, in which asymmetries are biased to one side of the organism; (2) the coin-toss hypothesis, which suggests that morphogenesis is made of independent developmental units: as randomly assigned developmental units increase, asymmetry decreases; (3) magnification of asymmetry, in which random asymmetries early in development are magnified during growth and development; (4) accumulation of accidents, in which developmental noise accumulates over time: asymmetry increases with the time it takes to develop a trait; (5) persistent asymmetries, in which size and direction of asymmetry are determined early on and are not altered among growth stages; and (6) compensational growth, which implies a regulatory feedback between left and right sides that reduces asymmetry with age.

As an environmental stress, nutrient variation may also affect developmental stability (Lappalainen et al. 2000; BlackSamuelsson and Andersson 2003). Deficiencies in nutrients 
such as nitrogen, phosphorous, and potassium lead to slower growth, alterations in shoot and root biomass, and changes in leaf coloration and development (Bottrill et al. 1970; Sultan and Bazzaz 1993; Yeh et al. 2000). However, any deviation from normal nutrient availability, whether increase or decrease, may result in decreased developmental stability (Lappalainen et al. 2000). The total FA often measured in stressed environments comprises the additive or synergistic effects of FA due to age (development) and FA due to stress, whether environmental or genetic. To get a true measure of FA due to stress alone, measurements should also account for ontogenetic effects of FA when comparing performance in different environments (fig. 1). FA due to development alone makes the assumption that growth occurs under optimal conditions and that the organism is taxed in the process of growth.

The objective of this study is to partition the contributions of development, environment, and genotype to FA. Our test was run on two wetland plant species, Lythrum salicaria and Penthorum sedoides, under two nutrient conditions. We investigated the effect of development (age) on leaf length, width, and FA in the two species, in addition to assessing responses to variable nutrient conditions and the possible additive or synergistic effects of age and nutrient variation. A test for genetic contributions to FA was included by conducting these tests among clones of multiple genotypes in both $L$. salicaria and $P$. sedoides.

\section{Material and Methods}

Lythrum salicaria (purple loosestrife) is an invasive species nonnative to North America that originated in Eurasia and was recorded from Canada and New England as long ago as 1814 (Mal et al. 1992). It is a perennial, dicot shrub found in marshes, sedge meadows, bogs, riverbanks, and roadside ditches. Penthorum sedoides (ditch stonecrop) is a native species of the eastern and midwestern United States. It is a perennial, dicot herb found in stream banks, roadside ditches, and other low, wet places. Therefore, each species can be found to cover a variety of habitats and is exposed to diverse stresses. The leaves of both are bilaterally symmetrical, allowing a straightforward means of measuring FA (fig. 2).

Thirty genotypes of each species were germinated in an indoor facility; each genotype was cloned to produce six identical plants that were grown indoors for $8-9$ wk before being moved outdoors. These 360 plants were randomly numbered and placed in numerical order in an outdoor experimental area on the Cleveland State University campus (fig. 3). Six clones of each genotype were selected and prescribed one of two nutrient treatments. One treatment group received no nutrients, and the other group received the commercial fertilizer Miracle-Gro in the proportion of one tablespoon per gallon of water, with $375 \mathrm{~mL}$ of the fertilizer solution added to each plant per treatment. Fertilizer treatments began when the clones were $11 \mathrm{wk}$ of age, and treatments were repeated every $2 \mathrm{wk}$, at ages 13,15 , and $17 \mathrm{wk}$.

At week 11, before nutrient treatment, the largest healthy leaf of each plant was sampled and pressed in a herbarium for later measurement. Ten weeks later, the largest healthy leaf from each plant was collected and pressed. The width of each sampled leaf was measured with digital calipers (Mitutoyo Absolute Digimatic CD-6"CS) at the widest point of the lamina. The widths of the left and right halves were measured from the midrib to the leaf margin, and the length of the lamina was also measured (fig. 2). All measurements were repeated for accuracy; the second set of measurements was taken on different dates and in a different order to reduce bias. The average of the two measurements was used in all analyses.

Statistical analysis. To determine the treatment and genetic effects on leaf morphology and specifically asymmetry, FA was calculated as $|\log L-\log R|$ to account for size differences in FA (Graham et al. 2003). The FA data were Box-Cox transformed using the equation $(|\log L-\log R|+0.00005)^{0.33}$ (Freeman et al. 1999) because using the absolute value of $(L-R)$ results in a half-normal distribution (Freeman et al. 2003). Hereafter, the Box-Cox-transformed FA is referred to as BCFA.

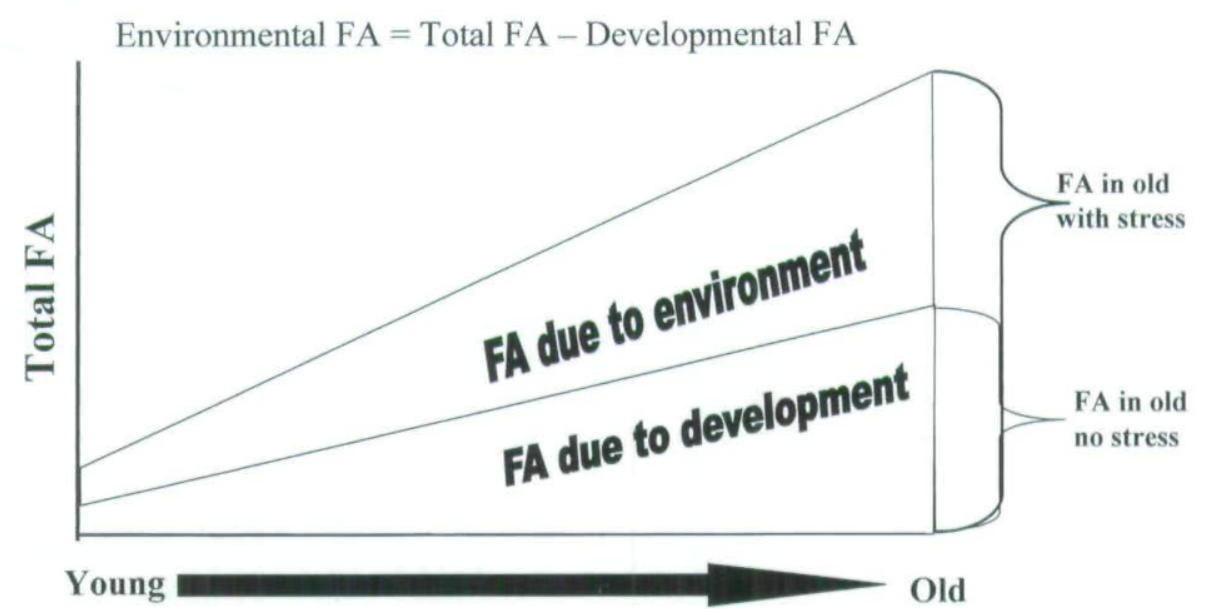

Fig. 1 Possible additive and synergistic effects of age and stress on fluctuating asymmetry (FA) of an organism. FA due to development alone assumes development under optimal conditions. FA due to environment refers to the increase in asymmetry due to additional environmental stress. Genetic background is assumed to be unimportant. 


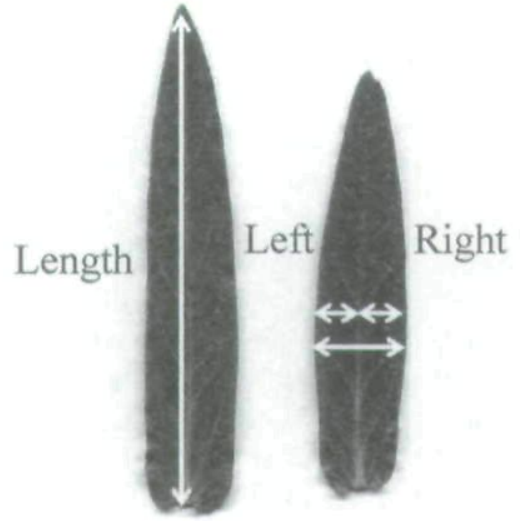

Total Width

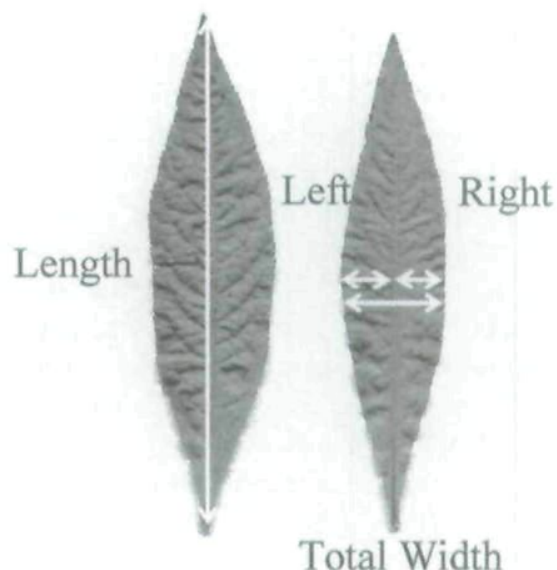

Ditch Stonecrop

\section{Purple Loosestrife}

Fig. 2 Example of leaf measurements of length, width, and asymmetry in both purple loosestrife and ditch stonecrop.

For each species, two-way ANOVAs were run to test for the effects of genotype, treatment, and genotype by treatment interaction on leaf length, leaf width, and BCFA. Random effects (genotype) and the fixed (treatment) effect were tested against the genotype by treatment interaction mean square. To determine the effects of development (age), a one-sample $t$-test was run on the difference between old leaves and young leaves for length, width, and BCFA in both fertilized and unfertilized plants. To discern the nutrient effects on the three characters while accounting for effects of age, a two-sample $t$-test was run on the differences between old and young leaves, grouping them by nutrient treatments. All statistical analyses were carried out using SYSTAT 8.0 (SPSS, Chicago).

\section{Results}

FA (measured as BCFA) did not have a genetic component in either Lythrum salicaria or Penthorum sedoides. Asymmetry levels were similar and not significantly different among

\section{Cleveland State outdoor experimental plots}

\section{Old power plant}

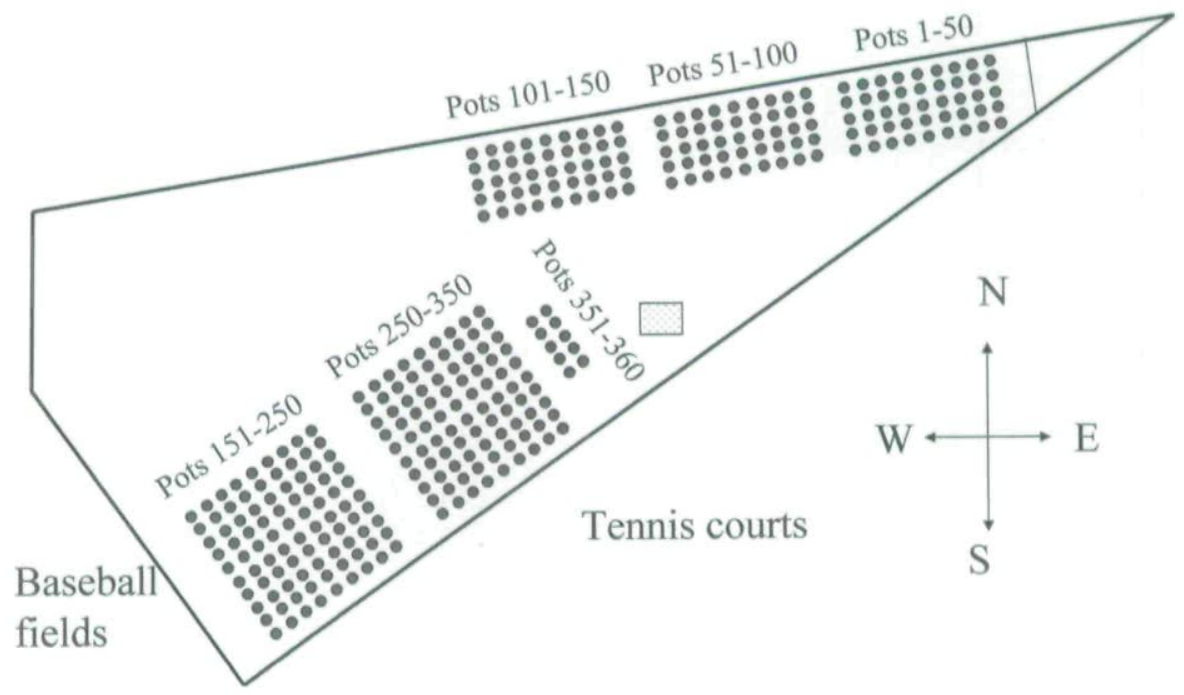

Fig. 3 Diagram of experimental plot area, demonstrating position of randomly numbered pots. 
randomly chosen genotypes of both species under both nutrient conditions, producing no significant main effects. Furthermore, there were no significant interactions between genotype and treatment for this trait in either species. However, leaf size varied genetically. In L. salicaria, size of leaves combined across young leaves, old leaves without nutrient treatment, and old leaves with nutrient treatment differed significantly by genotype for leaf length $\left(F_{29.58}=3.08, P<0.001\right)$ and leaf width $\left(F_{29,58}=4.02, P<0.001\right)$. The interaction between genotype and treatment was also significant for both size traits ( $F_{58,260}=2.1, P<0.001$ for length; $F_{58,260}=1.7, P<0.01$ for width). In contrast, size of leaves in $P$. sedoides did not differ significantly among genotypes as a main effect for length $\left(F_{29,58}=1.26\right.$, not significant $)$ or width $\left(F_{29,58}=1.21\right.$, not significant), but there was interaction effect between genotype and treatment for width $\left(F_{58,231}=1.50, P<0.05\right)$.

Leaf size in both species was significantly affected by treatment. In L. salicaria, nutrient addition increased leaf length but not leaf width (table 1 ). In $P$. sedoides, both leaf length and leaf width increased because of nutrient treatment when age was taken into account (table 1).

In contrast to the lack of genotypic effects on FA, a significant effect of treatment occurred for BCFA in L. salicaria $\left(F_{2,58}=5.9, P<0.01\right)$ and $P$. sedoides $\left(F_{2,58}=8.4, P<0.001\right)$. BCFA in L. salicaria was significantly larger for young leaves than for older leaves without fertilizer. However, when fertilizer was added, the difference in asymmetry between young leaves and old leaves was no longer significant (table 1). BCFA in $P$. sedoides was also significantly larger in young leaves than in old leaves whether plants received added nutrients or not (table 1).

\section{Discussion}

Both growth and nutritional stress may affect leaf FA independent of genetic background. In Lythrum salicaria, nutrient enhancement appeared to be a contributor to FA as leaves matured, while age had an inverse effect. This development, however, was the main factor contributing to reduced FA in
Penthorum sedoides, because the addition of fertilizer did not influence leaf asymmetry. In neither species did genetic background contribute to variation in asymmetry directly or as an interactive factor with age and nutrition.

\section{Age}

Age (survivorship/growth) has been directly related to developmental stability (Møller and Swaddle 1997), where the trend is for less asymmetry with age in animals (Naugler and Leech 1994; Ueno 1994; Swaddle and Witter 1997). The animals that survive may be those least affected, and analysis of adults may bias estimates of FA. By contrast, plants may be more tolerant of developmental errors and therefore express greater asymmetry in older leaves (Freeman et al. 1994). However, of the few studies that have investigated the relationship between age and developmental stability in plants, size-corrected leaf asymmetry decreased with age in leaves (Pélabon et al. 2006), which is in accord with the diminished FA we observed, except where L. salicaria was grown in a high-nutrient environment. These faster-growing, larger leaves expressed asymmetry levels similar to those of young leaves.

Two of Swaddle and Witter's (1997, p. 329) "nonmutually exclusive hypotheses" are the most likely candidates to explain the development of leaf FA: the compensational-growth hypothesis and the coin-toss hypothesis. During juvenile stages, under optimal growth conditions, plants have a faster growth rate that decreases with time (Koelewijn 2004). Rapid growth may influence developmental stability, and as a result, there may be trade-offs between growth and the plants' ability to correct errors in development (Pélabon et al. 2006). Because plant growth occurs by adding new cells to older ones and by cell expansion, asymmetries would accumulate with age if regulatory feedback mechanisms were not present (Freeman et al. 2003). A study conducted on Cucurbita pepo L. (pumpkin) concluded that leaves are subject to feedback mechanisms (Freeman et al. 2003). Covering half the leaf with foil to perturb growth resulted in leaf asymmetries, but these asymmetries gradually declined over time. Randomly assigned developmental units, as in the coin-toss hypothesis, seem less

Table 1

Fertilizer Treatment Effects on Lythrum salicaria and Penthorum sedoides

\begin{tabular}{|c|c|c|c|c|c|c|}
\hline & \multicolumn{2}{|c|}{$\Delta$ Length $(\mathrm{mm})$} & \multicolumn{2}{|c|}{$\Delta$ Width (mm) } & \multicolumn{2}{|c|}{$\triangle \mathrm{BCFA}$} \\
\hline & Mean $\pm 1 \mathrm{SE}$ & $P$ & Mean $\pm 1 \mathrm{SE}$ & $P$ & Mean $\pm 1 \mathrm{SE}$ & $P$ \\
\hline \multicolumn{7}{|l|}{ L. salicaria: } \\
\hline$\Delta$ (old - young), unfertilized & $20.65 \pm 2.53$ & $<.0001$ & $1.61 \pm .48$ & $<.01$ & $-.038 \pm .014$ & $<.01$ \\
\hline$\Delta$ (old - young), fertilized & $33.57 \pm 2.46$ & $<.0001$ & $2.14 \pm .57$ & $<.001$ & $-.004 \pm .015$ & ns \\
\hline $\begin{array}{l}\text { Comparison of } \Delta \text { for fertilizer } \\
\text { treatments }\end{array}$ & $12.92 \pm 3.55$ & $<.001$ & $.52 \pm .74$ & ns & $.035 \pm .02$ & ns \\
\hline \multicolumn{7}{|l|}{ P. sedoides: } \\
\hline$\Delta$ (old - young), unfertilized & $12.20 \pm 3.04$ & $<.001$ & $7.49 \pm .84$ & $<.0001$ & $-.047 \pm .013$ & $<.01$ \\
\hline$\Delta$ (old - young), fertilized & $24.52 \pm 3.39$ & $<.0001$ & $11.52 \pm .94$ & $<.0001$ & $-.027 \pm .012$ & $<.05$ \\
\hline $\begin{array}{l}\text { Comparison of } \Delta \text { for fertilizer } \\
\text { treatments }\end{array}$ & $12.33 \pm 4.86$ & $<.05$ & $4.04 \pm 1.34$ & $<.01$ & $.021 \pm .01$ & ns \\
\hline
\end{tabular}

Note. Mean change in length, width, and BCFA (Box-Cox-transformed fluctuating asymmetry) between old and young plants and for the effect of fertilizer treatments, accounting for the effect of age, in L. salicaria and P. sedoides. Tests for significance of $\Delta$ (old - young) unfertilized and $\Delta$ (old - young) fertilized used one-sample $t$-tests. Comparison of $\Delta$ for fertilizer treatments used a two-sample $t$-test. $\mathrm{ns}=$ not significant. 
likely to correct large asymmetries. The directional-external-cues hypothesis states that asymmetry will be consistently biased toward the same side of the organism, with no prediction as to the magnitude of asymmetry. We did not examine that bias in this experiment.

\section{Nutritional Stress}

The initial impetus for our study was the possibility of using FA as a measure of environmental stress. Variation in nutrient availability could lead to an increase in plant asymmetry either because of stresses on growth from insufficient nutrients or because of toxic levels of nutrients following enrichment. Studies on sweet flag (Acornus calamus L.) demonstrated that moderate increases in nitrogen positively affect growth, but, at highnitrogen treatments, negative effects on growth presented themselves (Vojtíšková et al. 2004). Nutrient addition had a significant positive effect on leaf size in both L. salicaria and $P$. sedoides but did not significantly alter leaf asymmetry in older leaves of $P$. sedoides and had only a very weak effect on L. salicaria leaf asymmetry. In one of the previous studies on the effects of nutrients on leaf asymmetry, Black-Samuelsson and Andersson (2003) investigated FA in maple (Acer plantanoides) and birch (Betula pendula) in low- and high-nutrient treatments. In both trees, nutrient addition positively affected leaf size and resulted in increased mean absolute asymmetry. Nevertheless, when leaf asymmetry was adjusted to account for size differences, the effects of nutrients were no longer significant. In another study of varying nutrient enrichment, Lappalainen et al. (2000) found an increase in asymmetry after nutrient enrichment in birch. Correspondingly, Andalo et al. (2000) found greater asymmetry in birdfoot trefoil (Lotus corniculatus), a grassland species, raised in elevated nitrate and carbon dioxide. Our result for the wetland species $L$. salicaria agreed with those findings. It is possible that the rapid growth associated with nutrient enrichment reduces an organism's ability to correct subtle asymmetries.

\section{Genetic Effects}

The potential for a genetic basis of FA remains one of the most contentious issues surrounding the application of this character to studies of plant stress in nature (Leamy and Klingenberg 2005). The variation in leaf length and leaf width among clones of $L$. salicaria or $P$. sedoides clearly demonstrates that the experimental material was genetically variable; however, no genetic basis for FA was found under the growth conditions used. Sultan and Bazzaz (1993) also demonstrated that genotypes of different populations of Polygonum persicaria react similarly along a nutrient gradient for leaf area and mean leaf size. Only in treatments of extremely high nutrition was genetically based variation observed. Likewise, no additive genetic variation of leaf or ramet FA was found in half-sibling families of birch (Wilsey et al. 1998; Wilsey and Saloniemi 1999), and no significant effect of genotype was found for leaf or flower asymmetry in L. corniculatus (Andalo et al. 2000). Even in Drosophila melanogaster, additive genetic variation for FA in wing length was not found (Scheiner et al. 1991). These results suggest that genetic variation for nutrient-dependent growth characteristics is common; however, FA may not be greatly affected. Nonetheless, Leamy and Klingenberg (2005) hypothesize that FA levels can be influenced by dominance and epistatic interactions among the numerous genes that affect growth, but the presence of buffering systems may prevent deleterious alleles from disrupting development (Rutherford and Lindquist 1998; Milton et al. 2003).

\section{Conclusions}

Increased nutrient levels led to slightly higher leaf asymmetry in L. salicaria, but for the same treatment, FA was unchanged for $P$. sedoides. It is possible that the degree of nutrient stress imposed on L. salicaria and P. sedoides was not great enough to elicit a strong response in terms of FA and that a nutritional gradient examining greater extremes of nutrient stress would better serve to describe potential responses in FA. The use of FA as an assessment tool for environmental stresses should be encouraged because under standard growth conditions and with added nutrition, there was no genetic basis for FA. Anthropogenically induced nutrient enrichment is known to negatively affect wetland ecosystems by altering interspecific relationships and species composition in the long term (Pauli et al. 2002; Vojtíšková et al. 2004). FA in L. salicaria may therefore be a better short-term indicator of nutrient enrichment in wetland ecosystems; however, the utility of FA in $P$. sedoides needs supplementary investigation. We further suggest that the age of a population being sampled must be considered when using asymmetry as an indicator of environmental stress. The magnitude of FA appears to be species specific rather than genotype specific, and a possible approach for sampling stress in natural populations therefore may be to examine multiple species along an environmental gradient.

\section{Acknowledgments}

J. R. Milligan would like to thank her advisory committee, John Holcomb and Michael Walton, for advice and guidance. In addition, we thank Kaloyan Ivanov for help collecting the data and especially Ann Nicholls for growing, cloning, and caring for the plants.

\section{Literature Cited}

Andalo C, A Bazin, JA Skykoff 2000 Is there a genetic basis for fluctuating asymmetry and does it predict fitness in the plant Lotus corniculatus grown in different environmental conditions? Int $\mathrm{J}$ Plant Sci 161:213-220.

Black-Samuelsson S, S Andersson 2003 The effects of nutrient stress on developmental instability in leaves of Acer platanoides (Aceraceae) and Betula pendula (Betulaceae). Am J Bot 90:1107-1112.
Bottrill DE, JV Possingham, PE Kriedemann 1970 The effect of nutrient deficiencies on photosynthesis and respiration in spinach. Plant Soil 32:424-438.

Freeman DC, ML Brown, M Dobson, Y Jordan, A Kizy, C Micallef, LC Hancock, JH Graham, JM Emlen 2003 Developmental instability: measures of resistance and resilience using pumpkin (Cucurbita pepo L.). Biol J Linn Soc 78:27-41. 
Freeman DC, JH Graham, JM Emlen 1994 Developmental stability in plants: symmetries, stress, and epigenesis. Pages 99-120 in TA Markow, ed. Developmental instability: its origins and evolutionary implications. Kluwer Academic, Dordrecht.

Freeman DC, JH Graham, M Tracy, JM Emlen, CL Alados 1999 Developmental instability as a means of assessing stress in plants: a case study using electromagnetic fields and soybeans. Int J Plant Sci 160(suppl):S157-S166.

Graham JH, K Shimizu, JM Emlen, DC Freeman, J Merkel 2003 Growth models and the expected distribution of fluctuating asymmetry. Biol J Linn Soc 80:57-65.

Koelewijn HP 2004 Rapid change in relative growth rate between the vegetative and reproductive stage of the life cycle in Plantago coronopus. New Phytol 163:67-76.

Lappalainen JH, J Martel, K Lempa, B Wilsey, V Ossipov 2000 Effects of resource availability on carbon allocation and developmental instability in cloned birch seedlings. Int J Plant Sci 161:119-125.

Leamy LJ 1997 Is developmental stability heritable? J Evol Biol 10: 21-29.

2003 Dominance, epitasis, and fluctuating asymmetry. Pages 142-156 in M Polak, ed. Developmental instability: causes, and consequences. Oxford University Press, Oxford.

Leamy LJ, CP Klingenberg 2005 The genetics and evolution of fluctuating asymmetry. Annu Rev Ecol Evol Syst 36:1-21.

Mal TK, J Lovett-Doust, L Lovett-Doust, GA Mulligan 1992 The biology of a Canadian weed. 100. Lythrum salicaria. Can J Plant Sci $72: 1305-1330$

Milton CC, B Huynh, P Batterham, SL Rutherford, AA Hoffmann 2003 Quantitative trait symmetry independent of Hsp90 buffering: distinct modes of genetic canalization and developmental stability. Proc Natl Acad Sci USA 100:13396-13401.

Møller AP, JP Swaddle 1997 Asymmetry, developmental stability, and evolution. Oxford University Press, Oxford.

Møller AP, R Thornhill 1997 A meta-analysis of the heritability of developmental stability. J Evol Biol 10:1-16.

Naugler CT, SM Leech 1994 Fluctuating asymmetry and survival ability in the forest tent caterpillar moth Malacosoma disstria: implications for pest management. Entomol Exp Appl 70:295-298.

Palmer AR 1994 Fluctuating asymmetry analyses: a primer. Pages 335-364 in TA Markow, ed. Developmental instability: its origins and evolutionary implications. Kluwer Academic, Dordrecht.

1996 Waltzing with asymmetry. BioScience 46:518-532.

Pauli D, M Peintinger, B Schmid 2002 Nutrient enrichment in calcareous fens: effects on plant species and community structure. Basic Appl Ecol 3:255-266.
Pedersen BH 1997 The cost of growth in young fish larvae, a review of new hypotheses. Aquaculture 155:259-269.

Pélabon C, TF Hansen, ML Carlson, WS Armbruster 2006 Patterns of asymmetry in twining vine Dalechampia scandends (Euphorbiaceae): ontogenetic and hierarchical perspectives. New Phytol 170: 65-74.

Polak M 2003 Developmental instability: causes, and consequences. Oxford University Press, Oxford.

Rutherford SL, S Linquist $1998 \mathrm{Hsp} 90$ as a capacitor for morphological evolution. Nature 396:336-342.

Scheiner SM, RL Caplan, RF Lyman 1991 The genetics of phenotypic plasticity. III. Genetic correlations and fluctuating asymmetries. J Evol Biol 4:51-68.

Schmalhauzen I 1949 Factors of evolution: the theory of stabilizing selection. University of Chicago Press, Chicago. (Repr. 1986.)

Sinclair S, AA Hoffmann 2003 Monitoring salt stress in grapevines: are measures of plant trait variability useful? J Appl Ecol 40: 928-937.

Sultan SE, FA Bazzaz 1993 Phenotypic plasticity in Polygonum persicaria. III. The evolution of ecological breadth for nutrient environment. Evolution 47:1050-1071.

Swaddle JP, MS Witter 1997 On the ontogeny of developmental stability in a stabilized trait. Proc R Soc B 264:329-334.

Ueno H 1994 Fluctuating asymmetry in relation to two fitness components, adult longevity and male mating success in a ladybird beetle, Harmonia axyridis (Coleoptera: Coccinellidae). Ecol Entomol 19: 87-88.

Vojtíšková L, E Munzarová, O Votrubová, A Řihová, B Juřicová 2004 Growth and biomass allocation of sweet flag (Acorus calamus L.) under different nutrient conditions. Hydrobiologia 518:9-22.

Wilsey BJ, E Haukioja, J Koricheva, M Sulkinoja 1998 Leaf fluctuating asymmetry increases with hybridization and elevation in tree-line birches. Ecology 79:2092-2099.

Wilsey BJ, I Saloniemi 1999 Leaf fluctuating asymmetry in tree-line mountain birches, Betula pubescens ssp. Tortuosa: genetic or environmentally influenced? Oikos 87:341-345.

Woods RE, CM Sgro, MJ Hercus, AA Hoffman 1999 The association between fluctuating asymmetry, trait variability, trait heritability and stress: a multiply replicated experiment on combined stresses in Drosophila melanogaster. Evolution 53:493-505.

Yeh DM, L Lin, CJ Wright 2000 Effects of nutrient deficiencies on leaf development, visual symptoms and shoot-root ratio of Spathiphyllum. Sci Hortic (Amst) 86:223-233.

Zakharov VM 1992 Population phenogenetics: analysis of developmental stability in natural populations. Acta Zool Fenn 191:7-30. 
Copyright of International Journal of Plant Sciences is the property of University of Chicago Press and its content may not be copied or emailed to multiple sites or posted to a listserv without the copyright holder's express written permission. However, users may print, download, or email articles for individual use. 